Research Article

\title{
Analysis of Urban Residents' Sports Consumption Demand Based on Intercepted Regression Model
}

\author{
Qing Liu (15) \\ Department of Physical Education, Suqian University, Suqian 223800, Jiangsu, China \\ Correspondence should be addressed to Qing Liu; 16013@squ.edu.cn
}

Received 2 November 2021; Accepted 23 November 2021; Published 6 December 2021

Academic Editor: Miaochao Chen

Copyright (C 2021 Qing Liu. This is an open access article distributed under the Creative Commons Attribution License, which permits unrestricted use, distribution, and reproduction in any medium, provided the original work is properly cited.

\begin{abstract}
At this stage, broadening the consumer market, upgrading the consumption system and gradually establishing a consumption-led development concept are key factors in promoting high-quality economic development. At the same time, China's macro economy is also experiencing another test. The rapid development of China's real estate market in recent years has attracted a large number of investors, and real estate prices have produced irrational and substantial increases. Behind the boom of the real estate market is a social system crisis driven by profiteering and the growing seriousness of real estate financial bubble. So exploring the mechanism of the influence of real estate prices on the upgrading of residents' consumption is important for the current stage of China. Therefore, it is important to investigate the mechanism of real estate price impact on consumer upgrading for the coordinated development of real estate industry and national economy. In this paper, we analyze and examine the theory on the consumption improvement by the literature survey method. We also summarize the present research on the correlation and the influence mechanism of the real estate price and the consumption improvement and choose the index which reflects the present state of the real estate industry and the consumption of the inhabitant. Besides the input indicators that qualitatively manage the impact of housing prices on the improvement of residents' consumption, we first use the descriptive statistics method to understand the level of the Chinese real estate market and improve consumer spending. Based on this, the descriptive statistical method is applied to define the current state of China's real estate market and the level of improvement in consumption, and to define the standard for improving consumption in China. On the other hand, based on the spatial and spatial spillover points of view, we use spatial analysis framework combined with exploratory spatial data analysis and GIS to investigate spatial correlation between consumption structure and housing price, and accurately reflect the spatial clustering status of the index by drawing. Moran dispersion plot and Lisa cluster plot, then the spatial Darwinian model, are used to investigate the impact of real estate prices on the increase in occupant consumption from a macro perspective.
\end{abstract}

\section{Introduction}

For a long time, adhering to the new development concept, always "people" oriented, with the supply-side structural reform as the main line, and constantly reforming and innovating the system, optimizing, and upgrading products, we have made good achievements in expanding the scale of consumption, improving the level of consumption, and upgrading the structure of consumption [1]. However, at the same time, we can also see that the institutional and institutional barriers that restrict the expansion and upgrading of consumption in China are still prominent. The degree of differentiation in development between regions is still large.
The diversity of the consumer market and the richness of consumption methods are still unable to meet the multi-level consumption needs of residents. Especially in recent years, the pulling effect of investment is gradually weakening with the improvement of infrastructure construction. And the lack of overall demand has brought negative impact on the economy [2]. At this time, only by continuously expanding consumer demand, increasing the consumption rate of residents, accelerating the change of China's economic growth mode, and improving the current situation of unbalanced development of demand, can we truly reflect the people-oriented scientific development concept and the development direction aiming at improving people's 
livelihood while ensuring high-quality economic development [3]. According to economic theory, income level and wealth stock have a dominant influence on residents' consumption structure, while the dual attributes of the real estate market in terms of consumption and investment determine its status and influence in the field of residents' household wealth and consumption. The characteristics of the real estate market, such as basic, value-added, and strong regional characteristics, also determine changes in housing prices. The real estate market has a significant impact on the total assets and asset structure of households [4].

The US-China trade war since 2018 has had an allencompassing, long-term, complex, and far-reaching impact on China's economy, while China's macro economy is facing huge challenges due to the current "new pneumonia" epidemic. This is not only reflected in the chaos and downturn of the real estate industry, but also in the market feedback of "high prices" and the current situation of unsatisfied consumers [5]. Behind the rapid development of China's real estate industry, the slowdown in traditional investment and the growing problems of overcapacity and debt constraints have led to a gradual slowdown in China's aggregate demand growth, with consumption upgrading gradually becoming one of the "new troika"[6]. As an important part of the national economy, residential consumption is an important bridge between the real estate market and the national economy. Therefore, does the rapid development of the real estate industry promote the upgrading of the residential consumption structure, or does it seriously distort the structure in the process of promoting economic development? The question of whether the rapid development of the real estate industry has promoted the upgrading of the consumption structure of residents and caused the downgrading of consumption, and whether it presents different effects on the consumption of residents in different regions, is the focus of this paper [7]. The total amount of financial assets held by urban households and their allocation structure have also undergone dramatic changes. The net value of financial assets held by Chinese residents per capita is more than triples from 36,000 Yuan in 2012 to 84,600 Yuan in 2020. The proportion of savings-based assets in the total financial assets of Chinese households decreases from $86.7 \%$ to $48.8 \%$ in 2020 , and the structure of financial assets held by households has shifted from a financial asset allocation structure dominated by savings-based assets to a diversified allocation of financial assets [8]. Even though China's savings rate has declined in recent years, it is still at a high level compared to the savings rate of $7.7 \%$ in 2020 in the US. The consumption rate of Chinese residents is only $38.8 \%$ at the end of 2020, compared to the consumption rates of other developed countries: $68 \%$ in the US, $52 \%$ in Germany, and $48.6 \%$ in South Korea. At this stage, the total amount of household assets of Chinese urban residents is gradually increasing. And the types of financial assets owned by households are also increasing, but the impact of financial assets on urban residents' household consumption is not stable [9]. Although the types of financial assets in the market have increased, the form of financial assets held by urban residents is still mainly in the form of savings, leading to an unbalanced distribution and underutilization of financial assets, which in turn inhibits urban household residents' consumption. At the macro level, the impact of financial assets on residents' consumption varies significantly by region and culture. At the micro level, the allocation of financial assets to residential households promotes or inhibits consumption of Chinese residents through the wealth effect or crowding-out effect [10]. In the past, due to the lack of data and the imperfection of financial markets, fewer Chinese scholars have studied the impact of financial asset allocation on household consumption, and most of them have done so from the macro level of financial assets, using macro data [11]. Even if the impact of financial assets on consumption is occasionally analyzed at the micro level, most of them focus on a particular financial asset and do not analyze the impact of each financial asset allocation on consumption in a very comprehensive way.

However, with the continuous opening of the financial market and the improvement of the investment channels provided by the financial market, people's allocation of financial assets tends to be diversified. And it is not representative to examine the impact of a single financial asset or a certain type of financial asset on household consumption. By studying the influence mechanism of house prices on consumption upgrading from a spatial perspective, we can investigate the correlation and heterogeneity of house price fluctuations and consumption upgrading between regions, which can provide differentiated and targeted suggestions for establishing a long-term mechanism of consumption upgrading between regions, improving residents' consumption level and optimizing residents' consumption structure. Thus, fundamentally improving residents' lives, promoting the improvement of consumption experience and consumption quality, helps the real estate industry to improve the status quo of real estate bubble, uphold the guiding ideology, implement correct strategic decisions and business models, and promote the efficient operation of real estate enterprise management and the high-speed and stable development of the real estate industry. It helps optimize the structure of the national economy, break the constraint system of housing prices on residents' consumption, and promote the coordinated development of residents' consumption and the real estate industry, thus promoting the macroeconomic. It also helps optimize the structure of the national economy, break the constraint system of housing prices on residents' consumption, and promote the coordinated development of residents' consumption and the real estate industry, thus promoting the progress of the macro economy.

In this paper, we analyze and examine the theory on the consumption improvement by the literature survey method and summarize the present research on the correlation and the influence mechanism of the real estate price and the consumption improvement and choose the index which reflects the present state of the real estate industry and the consumption of the inhabitant.

\section{Related Work}

In "A Trial on Consumption Structure Upgrade," the researchers suggest that consumption structure reflects the proportion and status of necessities and nonnecessities 
in residents' personal consumption, using food to refer to necessities and Engel's coefficient to measure residents' living standard and national development process [12]. In "The Key to Expanding Domestic Demand and Consumption Structure Upgrade is the Transformation of Three Groups of Consumer Goods", the researchers point out that different income classes will form different levels of consumption and thus different levels of supply of consumer goods [13]. The key to expanding domestic demand and upgrading consumption structure lies in the transformation of three consumer goods groups". Researchers point out that different income classes form different consumption levels, which in turn form different grades of consumer goods supply, and divide the demand levels of final consumer goods into high-end, terminal and low-end consumer goods groups. Researchers analyze with the help of household microsurvey data and conclude that the increase of residents' consumption comes from the increase of housing prices [14]. There is no difference between owner-occupied and rented households. And it is only related to the place of residence, age, and income of households. Researchers obtained from the study that the level of urbanization significantly affects the final decision of residents' consumption expenditure. Researchers used the gray correlation model method to obtain the conclusion that there is an intrinsic correlation between the age structure of the population and the upgrading of residents' consumption structure. Researchers in "Development trend of consumption upgrading and influencing factors" compared the changes of household consumption structure in the US, Japan, and Korea with those in China. And they suggested that the current consumption upgrading trend in China is obvious, but there are still problems such as slow upgrading, uneven income distribution, low consumption intention, and supply-side shortcomings [15].

By establishing an error correction model in which the dependent variable is consumer spending and the independent variables are salary and housing price, researchers use cointegration and Granger causality tests to obtain a common trend between house prices and consumption. And they also use variance decomposition and impulse response function to explore the magnitude of the effect of residential consumption on house price changes [16]. The results show that both the change in wage income and the increase in house price significantly boost the consumption of Hong Kong residents, with the increase in house price contributing more to the increase in consumption. Using the annual data from 1998 to 2007, the researchers developed an error correction model for house prices and consumption, and conducted an empirical analysis of the relationship between house prices and consumption. Researchers have used micro household survey data to find that the increase in real estate wealth has a "wealth effect" on residents' consumption. Researchers have studied Shanghai data to find that the increase in house prices has a positive effect on consumption. They have found that the increase in house prices significantly elevates residents' emerging consumption expenditure [17].
Researchers point out that the rising house prices have a clear "liquidity constraint" on residents' consumption. But the "desperate consumption effect" occurs when house prices are too high, causing residents to give up home consumption and switch to other alternative consumption, thus causing an increase in alternative consumption. Researchers through the study surveyed the 1983-2001 and 1990-2000 US macro data [18]. Researchers, through studies of US macro data from 1983 to 2001 and 1990-2000, have found that houses are similar to Giffen's goods. And, when prices rise, the number of purchasers increases. So, the rising house prices increase the high indebtedness of households in society as a whole. In fact, the greater marginal propensity to save leads residents to spend their appreciation gains on saving rather than on consumption [19]. Researchers have empirically found that house prices have a depressing effect on consumption and there is a "crowding-out effect". They have selected national data before and after the housing reform to conduct empirical analysis, and the results show that the increase in house prices has a crowding-out effect on consumption. They point out that the crowding-out effect on consumption is greater when house prices increase too fast [20]. The researchers concluded that residents choose to repay their mortgage early and purchase a home because they are concerned about the continued increase in house prices, which causes the crowding out of consumption in the current period. The researchers concluded that residents focus more on the investment properties of real estate when house prices continue to increase, which squeezes out other consumption [21].

\subsection{Transmission Mechanism of Housing Consumption.} The "crowding-out effect" of real estate refers to the increase in the cost of home ownership for potential home buyers or renters, resulting in a decrease in relative disposable income or relative savings, so that residents suppress consumption demand and continuously reduce nonhousing consumption expenditure, resulting in the "crowding-out effect" of housing prices on consumption. ". In Chinese society, due to certain income gap, some residents own one or even more houses, while some residents are still in the state of renting. For renters, the rising house prices cause rents to rise, which in turn squeezes nonhousing consumption expenditures. As a whole, the "squeeze effect" caused by the redistribution of wealth inhibits the upgrading of consumption, as shown in Figure 1. The budget constraint first refers to a firm's expenditure constrained by its money stock and income, and, by extension, a household's assets and income. So, a large part of residents' saving behavior is motivated by the prudential and precautionary principles. The rise in housing prices will increase the budgetary constraints of renters and residents in need of housing, prompting them to save more and consume less. There is a degree of substitutability between housing and nonhousing consumption in the market. Individuals who plan to purchase a home in the future may choose to reduce their current consumption and increase their savings in order to purchase a home as soon as possible in the face of rising housing prices and higher housing costs, 


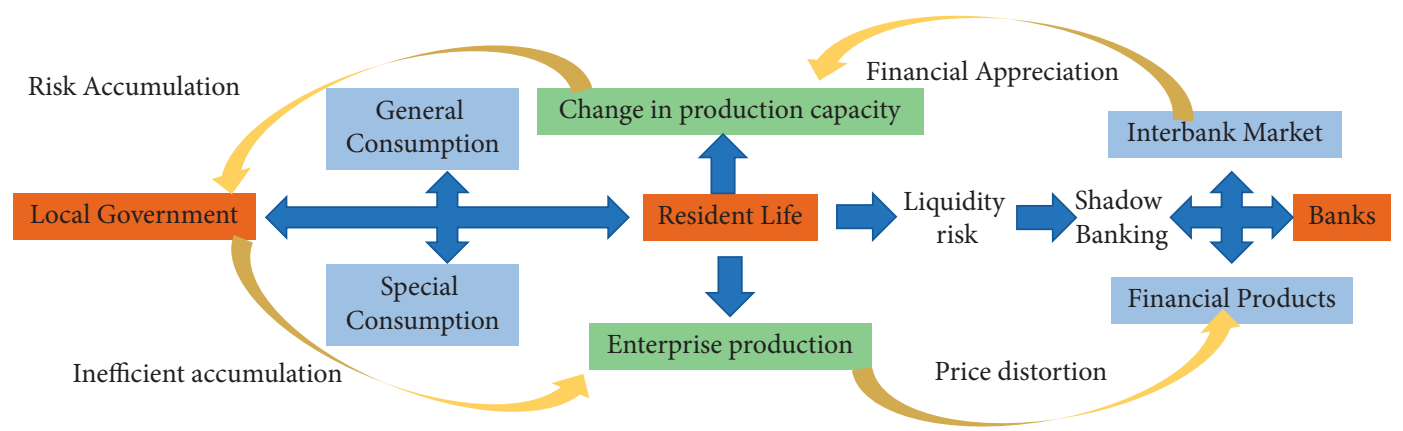

Figure 1: Transmission mechanism of housing consumption.

while some residents may be discouraged by high housing prices and simply give up purchasing a home and spend the money on other consumption to improve their living standards. The substitution effect is not necessarily a "squeeze effect", but also a "wealth effect". But at the same time, the high rise in housing prices will also increase the pressure of subsequent repayments, making residents significantly reduce nonhousing consumption expenditure and increase personal savings in order to reduce repayment costs and pay off the loan as soon as possible.

In the mortgage market, real estate serves as a high-quality collateral to liquidate residents' fixed assets into liquid money, thus increasing their consumption. However, the existence of liquidity constraints and collateral effects in the mortgage market has a negative impact on the upgrading of resident consumption. The existence of liquidity constraints greatly increases the sensitivity of residents to stock wealth and disposable income due to information asymmetry and incompleteness in credit markets. Rising housing prices imply a decline in residents' disposable income, which can lead residents to increase their savings to prevent future shocks from another decline in relative income or an increase in emergency consumption demand. Thus, making it difficult for residents to consume and invest the expected amount. Secondly, the traditional family culture concept such as "having a house is the only way to have a home", "having a house and a car for marriage" brings about an increase in the demand for purchasing houses, which makes more and more people become "house slaves" as the housing price rises, continuously squeezing out their own consumption and inhibiting the consumption upgrade of the whole society.

\subsection{Regression Model for Consumer Demand Analysis.} The target variables studied in this paper and their sample observations exhibit certain spatial aggregation characteristics, which are contrary to the basic assumption of no correlation between sample observations in traditional econometrics. If the target variables are modeled with traditional econometric models, it will lead to distorted data information and biased results. In this paper, we explore the correlation between house prices and consumption upgrading indicators by exploratory spatial data analysis (ESDA) method, and select the appropriate spatial weight matrix to be incorporated into the model construction to deeply investigate the spatial spillover effect and spatial heterogeneity of the impact of house prices on consumption upgrading. The spatial econometric models considered in this paper are mainly spatial panel lagged model (SLM), spatial panel error model (SEM), and spatial panel Durbin model (SDM), which incorporate different dimensions of spatial interactions in space, respectively, among which, the SDM model is a generalized form of SLM and SEM models. Spatial lag models, also called spatial autoregressive models, need to introduce endogenous interactions between regions of the explanatory variables for model construction if the explanatory variables have spatial autocorrelation and are influenced by variables in other regions within the region delineated by the spatial weight matrix, to explore the correlation between the explanatory variables in the region and the explanatory variables in neighboring regions, modeled as follows:

$$
T_{x}(u, x)=\frac{\lim _{n \longrightarrow \infty} \sum_{i=1}^{n} x_{i} y_{i}}{\sqrt{(x+m)(x-m)}},
$$

where $Y_{i t}$ and $y_{j t}$ denote the observed values of the explanatory variables in the target region and their neighboring regions, respectively, $i$ and $j$ are cross-sectional dimension data, $t$ is the time dimension data, $w_{i j}$ denotes the spatial weight matrix elements between regions $i$ and $j, x_{i t}$ is the sample observation of the explanatory variables, denoting the column vector of regression coefficients, and $i$ is the individual fixed effect, and it is the random error term.

$$
\lim _{n \longrightarrow \infty} \sum_{i=0}^{m} f_{i j}=\frac{\oint_{L}\left[f_{i j}+q_{i j}\right] \mathrm{d} s}{W_{Q_{p}}} .
$$

The spatial error model, also called the spatial autocorrelation model, introduces interaction effects between error terms and reveals the exogenous spatial interaction effects contained in the unobservable error terms in the effects of the explanatory variables on the explained variables, modeled as follows:

$$
E_{x}(u, x)=\lim _{n \longrightarrow \infty} \sum_{i=1}^{n} x_{i} y_{i} \otimes T(i, j),
$$

where the newly introduced variable $u_{i t}$ denotes the spatial error autocorrelation and $\lambda$ is the autocorrelation coefficient.

The spatial Durbin model is a general form of spatial lag model and spatial error model, which is the result of the joint 
action of endogenous and exogenous explanatory variables as well as spatial error terms, focusing on revealing the correlation between the spatial error terms of independent variables and dependent variables, modeled as follows:

$$
\begin{aligned}
g_{i} & \left.=\mid \text { User }_{i}: k_{1}, k_{2}, \ldots k_{i}\right\rangle, \\
Q(w) & =C_{t}\left\{t_{1}, t_{2}, \ldots t_{i}\right\},
\end{aligned}
$$

where, $\tau$ is the column vector of regression coefficients. In order to reasonably quantify the spatial influence effect of house prices on consumption upgrading, this paper will set the appropriate spatial weight matrix and choose the appropriate spatial econometric model by each test.

The selection of spatial weight matrix has different significance to the empirical results of spatial econometric analysis. And each weight element in the matrix represents different spatial dependencies. Based on the guidelines of spatial weight matrix design, it is mainly divided into the categories of adjacency, geographic distance, and economic distance, which contain spatial adjacency weight matrix, geographic distance weight matrix, geographic distance square matrix, economic weight matrix, and economicgeographic nested matrix. In this paper, we select the spatial adjacency weight matrix $t_{1}$, geographic distance weight matrix $t_{2}$, and economic-geographic nested matrix $t_{3}$ as three different types of weight matrices with spatial recurrence effect for empirical study. And we select the most suitable spatial weight matrix for in-depth analysis of the spatial dependence of the research object. The spatial adjacency weight matrix, that is, $0-1$ matrix, is the most widely used spatial weight matrix, which is set according to whether the target regional units are adjacent or not. And it is suitable for research problems with more obvious regional boundary characteristics, and it is constructed on the following basis:

$$
g_{i}=\left\{\text { guest }_{i}, \ldots \text { guest }_{q}\right\} .
$$

Tobler's first law of geography states that "everything is related to everything else, but there is a closer connection between things that are close to each other". The matrix is constructed based on the following basis and matrix form:

$$
\begin{aligned}
& U_{2}=P\left(\alpha_{i}\right) \frac{Q-S}{L}+P\left(\gamma_{j}\right)=0, \\
& U_{2}=P\left(\alpha_{i}\right) \frac{Q-S}{L},
\end{aligned}
$$

Where $U_{2}$ is the geographic distance between geographical unit $i$ and geographical unit $j$ (either regional center-of-mass distance or regional administrative district center-of-mass distance can be chosen), and the elements in the geographic distance weight matrix correspond to the inverse of the geographic distance between regions. The economic-geographic nested matrix is a weight matrix that contains both geographic distance factors and economic factors. For this paper, in addition to the influence of geographic proximity factors, China's consumption upgrade and house price distribution will also be influenced by economic factors to some extent. So, economic factors are introduced to construct the nested matrix. The distance information and economic information are incorporated into the model together, and the matrix is constructed based on the following:

$$
Q=\lim _{m \longrightarrow \infty} \sum_{i=0}^{m}\left[d_{i j}+f_{i j}\right]
$$

where $Q$ is the geographic distance weight matrix with diagonal elements in the matrix. And

$$
\operatorname{Im}(u, x)=\frac{\lim _{l \longmapsto \infty} \sum_{i=0}^{l} U_{x} K \times U_{m} K}{(x+m)(x-m)} .
$$

This paper uses Stata15.0 to construct the above spatial weight matrices and analyzes the effects of house prices and other control variables on consumption upgrading without spatial effects and with different weight matrices by constructing OLS models, spatial error models (SEM), and spatial lag models (SAR). It also compares the great likelihood estimates to determine the appropriate spatial weight matrices.

As shown in the results of Figure 2, firstly, from the perspective of with and without spatial effects, in the OLS model without spatial effects, the dependency ratio and social insurance rate indicators originally passed the $1 \%$ confidence test and had significant negative and positive effects on consumption structure upgrading, respectively. But, after adding spatial errors and lagged effects, the effects became insignificant under the effect of certain spatial weight matrices. Industrial structure upgrading also transformed from a negative inhibitory effect on consumption upgrading without spatial effects to a positive promoting effect with the inclusion of spatial effects.

As shown in Figure 3, the effect of the explanatory variables on the upgrading of consumption structure under different spatial effects is explored. Under the effect of the three spatial weight matrices, the coefficients of the core explanatory variables of house price on consumption structure upgrading are all negative and pass the $1 \%$ confidence test, showing a significant inhibitory effect. While the supply of consumer goods and the level of financial development show a significant inhibitory effect, the income of residents, wealth accumulation, house price to income ratio, and the level of urbanization development show a significant promoting effect. The $\rho$ coefficient of the spatial error model and the $\lambda$ coefficient of the spatial lag model both pass the $1 \%$ confidence test with high goodness of fit under the three weight matrices. That is, both the spatial error model and the spatial lag model are valid. And we tentatively believe that a spatial Durbin model that considers both the dependent variable and the spatial lag term of the independent variable is needed for the empirical analysis. From the great likelihood estimates, we can see that among the models constructed with different spatial weights, the Log-L values under the role of geographic distance weights are larger. So, it is more reasonable to choose the geographic distance weight matrix for the construction of the spatial econometric model. Meanwhile, the neighboring weight matrix with the weakest spatial correlation performance is selected for the 


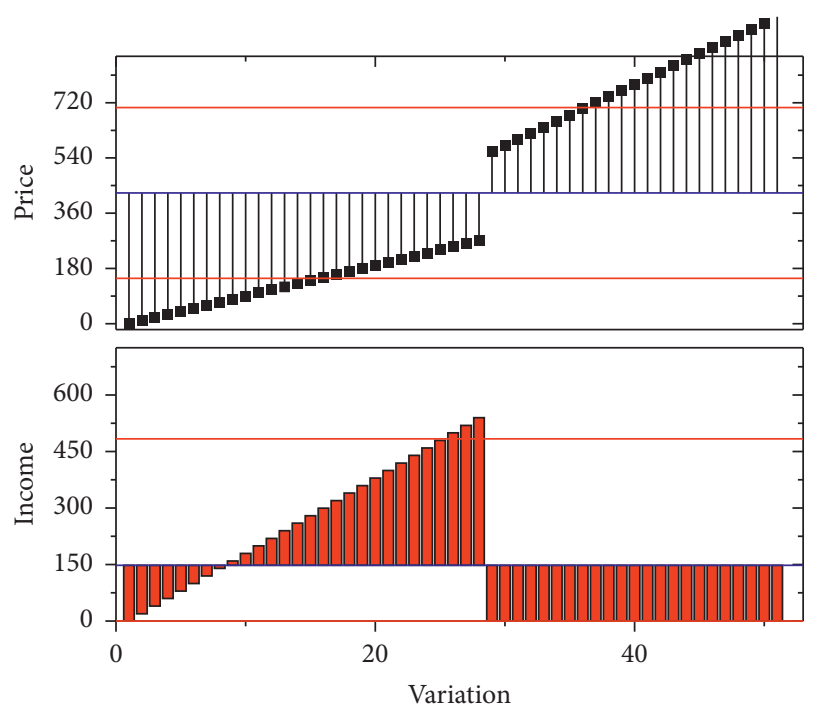

FIGURE 2: Estimation results of different models with different weights.

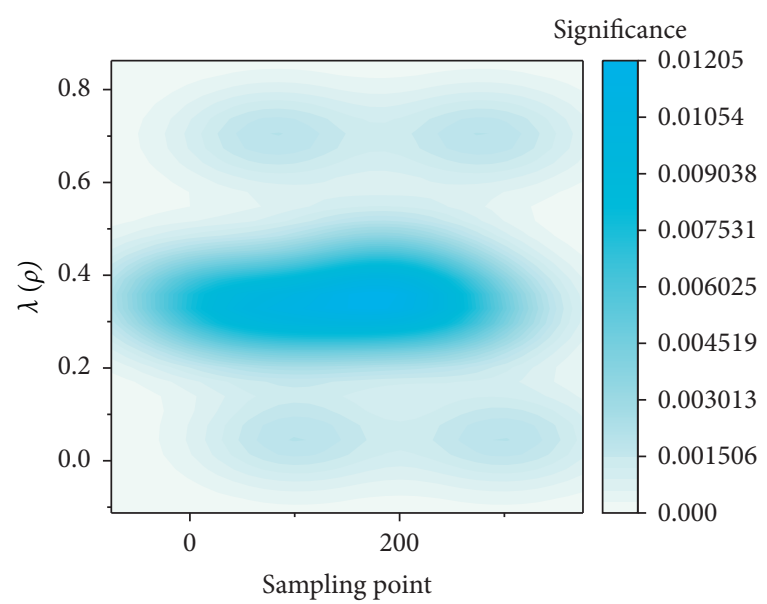

FIGURE 3: Significance of confidence level.

spatial autocorrelation test, and if the test passes, it means that the target variables must significantly exist in the study area spatial correlation.

2.3. Autocorrelation Test. The spatial spillover effect is the spatial autocorrelation, which refers to the spatial correlation and clustering characteristics of a factor in different geographical locations, while the spatial heterogeneity indicates the heterogeneity of the distribution of a factor in different geographical locations. In this paper, a spatial analysis framework combining exploratory spatial data analysis (ESDA) and geographic information system (GIS) is used to study the spatial correlation between consumption structure and house prices in China, and the global Moran's I statistic is used to measure the global spatial correlation coefficient between consumption structure and house prices in China, and the local Moran's I statistic is used to plot the spatial correlation coefficient between consumption structure and house prices in China. Moran's I is used to draw Moran's scatter diagram and LISA clustering diagram, and the analysis is organized to accurately and intuitively reflect the spatial clustering status of indicators. The global spatial autocorrelation analysis measures whether the spatially adjacent regional unit attribute variables are clustered from the whole regional study area and uses the value of Moran's index (Moran's I) to define the spatial correlation of indicators. Moran's index (Moran's I) is calculated by the formula

$$
\begin{aligned}
f_{i j} \leq 1, \quad i, j \in[0,9], \\
\lim _{q \longrightarrow \infty} \sum_{i=0}^{q} f_{i j} \leq \operatorname{Inf}\left\{W_{F_{i}}\right\},
\end{aligned}
$$

wheren denotes the number of study regions, $x_{i}$ and $x_{j}$ denote the sample observations of region $i$ and region $j$, respectively, and $w_{i j}$ is the standardized spatial weight matrix. This subsection uses the $0-1$ adjacency matrix for spatial autocorrelation analysis of the target variables. Moran's I is calculated as $[-1,1]$, if the value is greater than 0 . It indicates the existence of positive spatial correlation. And the closer it is to 1 , the stronger the positive correlation is, that is, the stronger the spatial clustering of the target variable. When the value is close to 0 , it indicates that the spatial distribution of the target variable tends to be random. That is, there is no spatial correlation. In this paper, we use GeoDa software to calculate the global Moran index and introduce the spatial adjacency weight matrix1W, as shown in Figure 4. From 2006 to 2018, the Moran index of consumption upgrade and house price indicators in China are positive. Except for 2014-2017, when the consumption structure passed the $10 \%$ significance test, all other indicators passed the $5 \%$ significance test, indicating that both indicators show a strong positive spatial correlation, that is, a strong aggregation characteristic. For residents with housing needs, mortgage loans are a good choice, and the sharp rise in housing prices will inevitably cause residents to expect high housing prices, prompting residents to suppress consumption demand and choose mortgage loans to purchase homes.

In order to reflect the spatial correlation between house prices and consumption structure in the overall region, the scatter plot of the correlation between house prices and consumption structure is drawn. Through comparison, it is found that the intercept term of consumption structure when house prices are zero in the scatter plot from 2006 to the present in China increases year by year, which indicates that the consumption structure in China is gradually upgrading. The slope of house price and consumption structure gradually decreases with the increase of house price level, and the increase of house price is gradually squeezing the process of consumption upgrading. In addition, there are several special values in the figure, including Tibet, where both consumption structure and house price are at low levels in 2006, 2014, and 2018, and Beijing and Shanghai, where house price and consumption structure are both far ahead in 2006 but significantly lower in 2014 and 2018 . 


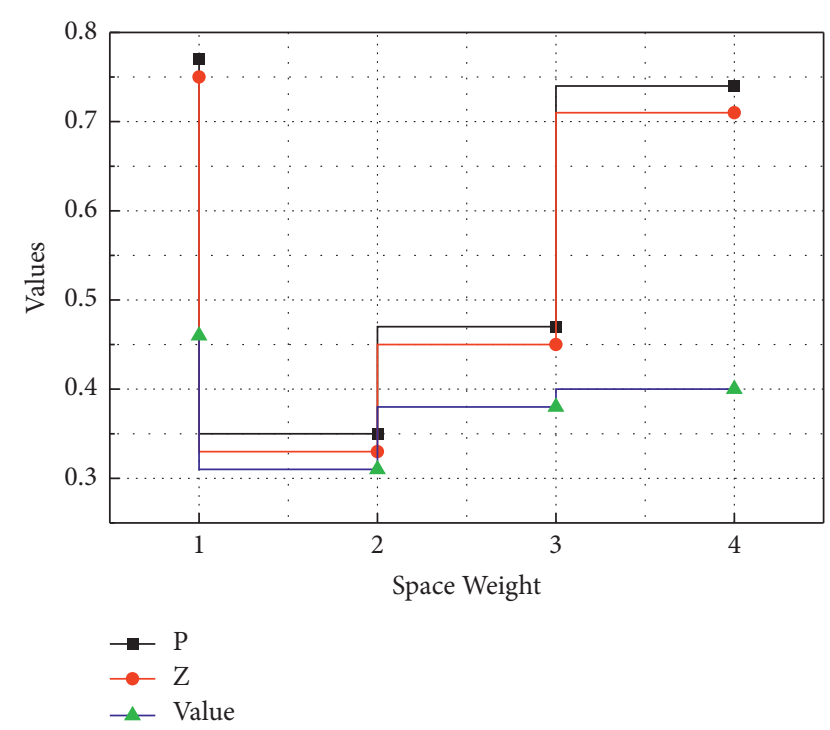

Figure 4: Consumption upgrade based on neighborhood space weight matrix.

\section{Regression Model Results and Autocorrelation Analysis}

For the target variable of consumption structure, in 2006, the cities of Hebei and Tianjin were influenced by the spatial spillover effect of the neighboring regions with high consumption structure and produced consumption upgrading, while Xinjiang, Qinghai, Tibet, Sichuan, and Yunnan were influenced by the spatial spillover effect of the neighboring regions with low consumption structure and produced consumption downgrading trends. In 2010, the new Jiangsu and Shanghai regions and their neighboring cities jointly showed high consumption structure. From 2014 to 2018, China's high-high agglomeration cities have changed significantly, and the high-high agglomeration feature is no longer significant in east-central China. The low-low agglomeration area in China also gradually develops from the southwestern region to the southeastern coastal region. Jiangxi, Fujian, and Zhejiang regions and their surrounding neighboring cities all show low-low distribution characteristics, while Gansu has a slow consumption structure upgrade, showing the characteristics of neighboring cities with high consumption structure but not spilling over high consumption levels to Gansu region. For the target variable of house price, in 2006, China only showed the trend of low-low aggregation of house price. Xinjiang, Qinghai, Gansu, and other regions with low level of house price and the neighboring regions showed the same low house price posture, while Tianjin in 2010, 2014, and 2018 showed the spatial spillover effect of its own high house price and high house price in the neighboring regions. Jiangsu Province in 2014 had the same high-high aggregation. At the same time, China gradually changed from a low-low house price aggregation trend in the southwest to a low-low house price aggregation trend in the northwest during the twelve years. In the actual study of spatial econometric models, the sequence of ordinary panel (OLS) models followed by spatial lag models (SAR) and spatial error models (SEM) and finally spatial Durbin models (SDM) is often followed to validate the discussion. Usually, before model selection, the spatial effects of the model are first selected. And, according to the different unobserved effects of the research object, the model can be roughly divided into fixed-effect model and random effect model, where the fixedeffect model is applicable to the research object with the same direction and effect size of the research results, and the random effect is applicable to the study of independent observed variables. In this paper, on the basis of ordinary OLS panel data, the Hausman test is conducted on the basis of the ordinary OLS panel data to test the validity of the panel data model settings under fixed effects and random effects. And the Hausman test value is 38.27 , which significantly passes the $1 \%$ confidence test, as shown in Figure 5, indicating that the research object is applicable to the fixed-effects model.

According to the different types of fixed coefficients in the regression equation, the spatial measurement fixed-effects model can be subdivided into individual fixed-effects model, time fixed-effects model, and time-individual double fixedeffects model. On the contrary, for time fixed effects versus individual fixed effects, the other unobservable deterministic variables vary only with time but not with individuals. For time-individual double fixed effects, the model is built with different intercept terms for different cross-sections (time points) and different intercept terms for different time series (individuals). In this paper, we first create three fixed-effects spatial Durbin models for comparative analysis and discussion. And we conduct LR test to discern whether the intercept terms of the models are significantly different for different cross-sections and different time series models. If the intercept terms are significantly different for different cross-sections and different time series models, then we need to choose the time-individual double fixed-effects model for relevant empirical studies. As shown in Figure 6, from the core explanatory variables, the direct effect of house price on consumption structure upgrading is -0.273 and the indirect effect is -1.640 , which pass the $1 \%$ and $5 \%$ confidence tests, respectively, indicating that the increase of house price will not only suppress the consumption structure upgrading in the region, but also squeeze the consumption in the neighboring regions, indicating that to some extent people have the fear of the increase of house price in the neighboring regions and expect the increase of house price in the region. To a certain extent, it indicates that people have a panic psychology about the increase of house prices in neighboring areas and expect that the house prices in the local area will also increase at some time in the future, thus causing residents in the local area to reduce consumption and lower the consumption level to counteract the pressure of home purchase caused by the increase of house prices.

From the perspective of regional economic development among the control variables, there is a strong correlation between the indicators of residents' income and the indicators of consumption structure upgrading, and both the direct and indirect effects. Residents' income shows a significant positive effect on consumption structure upgrading, as the penetration of the Internet into life is constantly blurring the boundaries of time and space, promoting the 


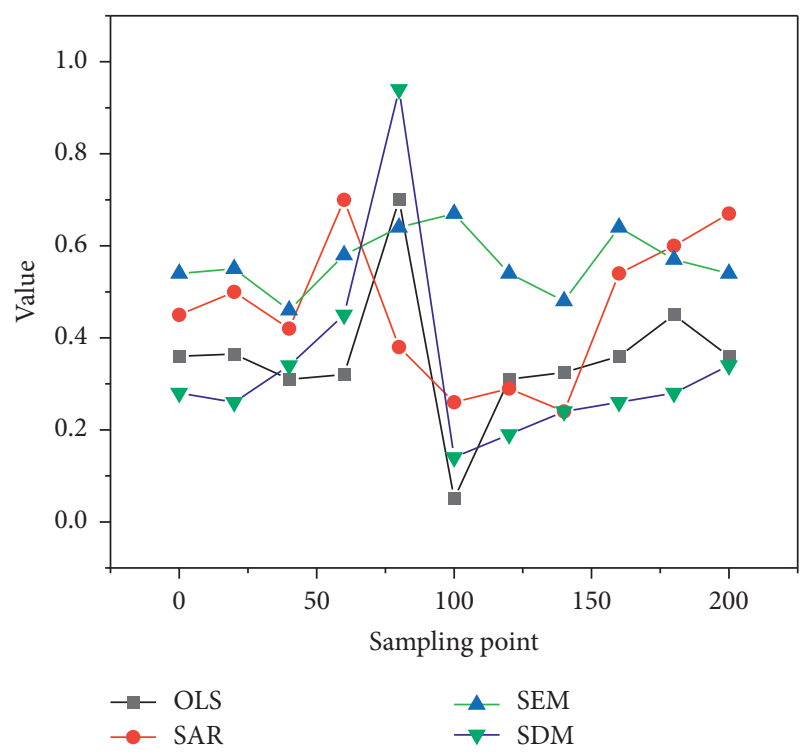

FIgURE 5: Spatial scatter plot of consumption structure.

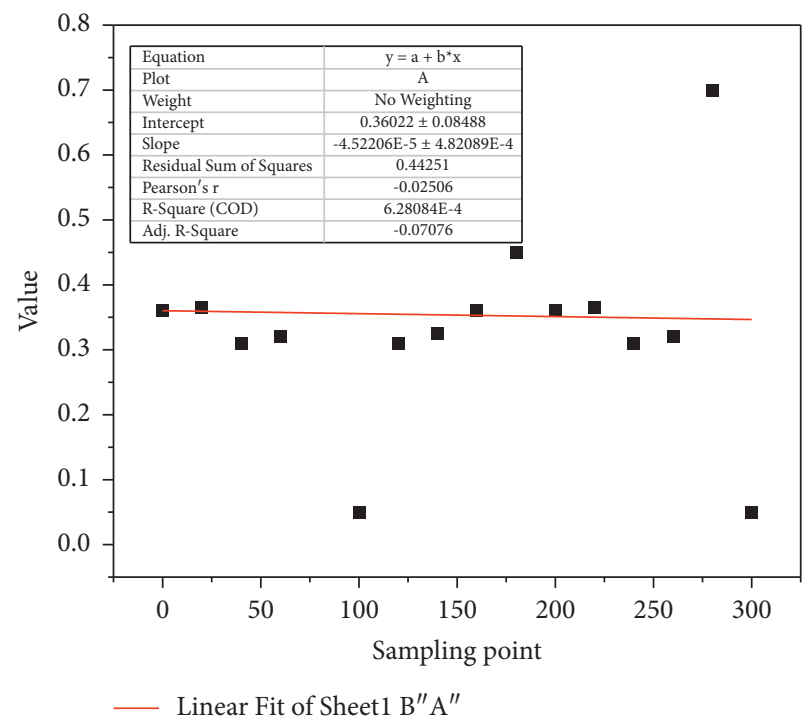

FIgURE 6: Spatial measurement fixed effects.

development of "borderless". As the penetration of the Internet into life is constantly blurring the boundaries of time and space, promoting the development of "borderless" consumption, the increase of income level in the region will not only promote the upgrading of the consumption structure level in the region, but will also promote the upgrading of the consumption structure in other regions to a greater extent. While the upgrading of industrial structure and the increase of the supply of consumer goods only have a significant positive promotion effect on the upgrading of the consumption system in the region, the inhibiting or promoting effect on neighboring regions is not significant. From the perspective of financial development among the control variables, the increase in the level of finance does not have a significant inhibitory or promotional effect on the upgrading of consumption structure in the region or neighboring regions, indicating that the level of regional financial

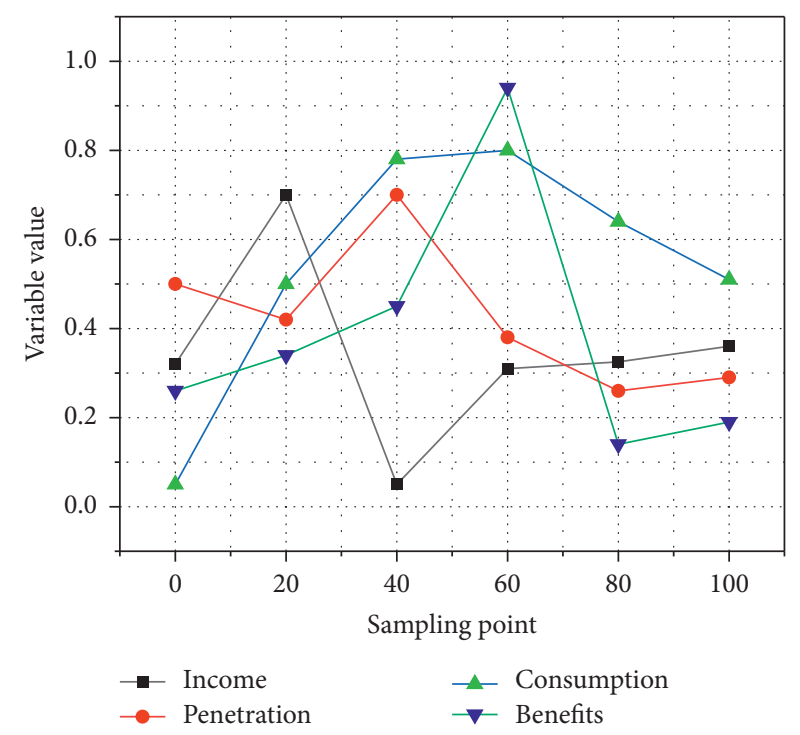

FIgURE 7: Consumption characteristics in control variables.

development does not significantly facilitate the upgrading of residents' consumption. The benefits of residents' use of financial instruments do not significantly offset the costs of using financial instruments. As shown in Figure 7, from the perspective of social security among the control variables, in terms of direct and indirect effects, the promotion effect of increasing the level of social security on consumption structure upgrading passes the test at the $10 \%$ confidence level, while overall 1 unit increase in the level of social security can upgrade the consumption structure by 0.436 units and passes the 5\% significance test, indicating appropriate and effective social security. This indicates that with proper and effective social security, the consumption structure of Chinese residents can be significantly improved.

From the perspective of the microindividual characteristics of the control variables, the increase in the level of wealth accumulation of Chinese residents significantly contributes to the upgrading of the consumption structure in the region. The increase in the value of the house price to income ratio indicator of Chinese residents, that is, the increase in the limitation of the purchasing power of residents' housing, significantly leads to the upgrading of the consumption structure at the $1 \%$ confidence level, meaning that most Chinese residents weigh their income against the level of house prices to measure the possibility of purchasing a home. And the less likely they are to purchase a home (the larger the house price to income ratio), the more likely they are to spend more of their income on consumption. The lower the likelihood of home ownership (the larger the house price to income ratio), the more likely they are to abandon their home ownership plans and instead spend more of their income on consumption, thus increasing the consumption structure hierarchy.

\section{Conclusion}

A well-developed financial market can help reduce the market frictions caused by rising house prices, while an adequate level of social security can reduce the income 
distribution gap caused by the wealth redistribution effect and the lack of consumption demand caused by the budget constraint effect and well coordinate the negative effects of rising house prices, causing strong market frictions and bringing about significant wealth redistribution effects and budget constraint effects. The rapid rise in housing prices in the east and central regions has led to increasing limitations on consumer housing purchases, eventually squeezing residents' consumption or even causing them to give up home purchases in favor of increased consumption. But, the increased consumption is not enough to offset the squeezed consumption, eventually leading to a significant squeeze effect of housing prices on consumption upgrading in the east and central regions. But because of the bubbling of housing prices in the east, the squeeze in the eastern region is more pronounced due to the more severe bubble in the eastern region. On the contrary, the rise in house prices in western China increases consumer confidence, making consumers anticipate a rise in the wealth effect and thus increase consumption or increase savings to reduce consumption in order to purchase a house, even though the market is not sound, but the wealth effect is still significantly higher than the squeeze effect, showing a significant positive promotion effect of house prices on consumption upgrading in western China. Overall, the overall impact mechanism of house prices on consumption upgrading in China behaves similar to that in the eastern region, with a combination of positive wealth redistribution effect and substitution effect and negative consumer expectations effect, eventually showing a significant negative impact.

\section{Data Availability}

The data used to support the findings of this study are available from the corresponding author upon request.

\section{Conflicts of Interest}

The authors declare that they have no known competing financial interests or personal relationships that could have appeared to influence the work reported in this study.

\section{Acknowledgments}

This work was supported by the key project of "College Students' Labor Education" from "Basic Courses Group" in Jiangsu Higher Learning Institutions 2021 (no. 2021JDKT029).

\section{References}

[1] X. Cheng, P. Dong, J. Shi, W. Qiu, C. Liu, and K. Wang, "Analysis on the consciousness of the early cancer diagnosis and its related factors among urban residents in China from 2015 to 2017," Chinese Journal of Preventive Medicine, vol. 54, no. 1 , pp. $62-68,2020$.

[2] Z. Ding, X. Jiang, Z. Liu, R. Long, Z. Xu, and Q. Cao, "Factors affecting low-carbon consumption behavior of urban residents: a comprehensive review," Resources, Conservation and Recycling, vol. 132, pp. 3-15, 2018.
[3] X. Qi, K. Zhang, N. Li et al., "Analysis on the health literacy of the cancer prevention and treatment and its related factors among urban residents in China from 2015 to 2017," Chinese Journal of Preventive Medicine, vol. 54, no. 1, pp. 76-83, 2020.

[4] Y. Han, L. Chatzidiakou, L. Yan et al., "Difference in ambientpersonal exposure to PM2.5 and its inflammatory effect in local residents in urban and peri-urban Beijing, China: results of the AIRLESS project," Faraday Discussions, vol. 226, pp. 569-583, 2021.

[5] Y. Han, W. Chen, L. Chatzidiakou et al., "Effects of Air Pollution on Cardiopulmonary Disease in Urban and PeriUrban Residents in Beijing: Protocol for the Airless Study," Atmospheric Chemistry and Physics, vol. 20, no. 24, pp. 15775-15792, 2020.

[6] Y. Lan, "The development of leisure sports consumption of urban residents under the view of marine ecological environment," Journal of Coastal Research, vol. 104, pp. 863-866, 2020.

[7] H. Li, K. Wang, Y. Yuan et al., "Analysis on the consciousness of the early cancer treatment and its influencing factors among urban residents in China from 2015 to 2017," Chinese Journal of Preventive Medicine, vol. 54, no. 1, pp. 69-75, 2020.

[8] C. Liu, C. Shi, J. Shi et al., "Study on the health literacy and related factors of the cancer prevention consciousness among urban residents in China from 2015 to 2017," Chinese Journal of Preventive Medicine, vol. 54, no. 1, pp. 47-53, 2020.

[9] X. Ma, "Labor market segmentation by industry sectors and wage gaps between migrants and local urban residents in urban China," China Economic Review, vol. 47, pp. 96-115, 2018.

[10] A. Mao, J. Shi, W. Qiu et al., "Analysis on the consciousness of the cancer early detection and its influencing factors among urban residents in China from 2015 to 2017," Chinese Journal of Preventive Medicine, vol. 54, no. 1, pp. 54-61, 2020.

[11] N. A. Smith, D. R. Voisin, J. P. Yang, and E. L. Tung, "Keepingyour guard up: hypervigilanceamong urban residents affected by community and police violence," Health Affairs, vol. 38, no. 10, pp. 1662-1669, 2019.

[12] P. Suthar, N. K. Joshi, and V. Joshi, "Study on the perception of swachhbharatabhiyan and attitude towards cleanliness among the residents of urban jodhpur," Journal of Family Medicine and Primary Care, vol. 8, no. 10, pp. 3136-3139, 2019.

[13] J. P. Aguilar Ticona, H. Baig, N. Nery et al., "Risk of sexually transmitted zikavirus in a cohort of economically disadvantaged urban residents," The Journal of Infectious Diseases, vol. 224, no. 5, pp. 860-864, 2021.

[14] F. Tzelepis, C. L. Paul, R. W. Sanson-Fisher et al., "Unmet supportive care needs of haematological cancer survivors: rural versus urban residents," Annals of Hematology, vol. 97, no. 7, pp. 1283-1292, 2018.

[15] K. Wang, C. Liu, A. Mao et al., "Analysis on the demand, access and related factors of cancer prevention and treatment knowledge among urban residents in China from 2015 to 2017," Chinese Journal of Preventive Medicine, vol. 54, no. 1, pp. 84-91, 2020.

[16] L. Wang, H. Z. Li, C. Zhu et al., "Results and cost-effectiveness of colorectal cancer screening program among urban residents in Zhejiang Province, 2013-2018," Chinese Journal of Epidemiology, vol. 41, no. 12, pp. 2080-2086, 2020.

[17] Y. Q. Wang, H. Z. Li, L. Wang et al., "Analysis of liver cancer screening results and influencing factors of urban residents in Zhejiang Province from 2013 to 2018," Chinese Journal of Preventive Medicine, vol. 55, no. 3, pp. 346-352, 2021. 
[18] Z. Wang, X. Dong, and J. Yin, "Antecedents of urban residents' separate collection intentions for household solid waste and their willingness to pay: evidence from China," Journal of Cleaner Production, vol. 173, pp. 256-264, 2018.

[19] L. Xu, S. Cui, J. Tang, X. Yan, W. Huang, and H. Lv, "Investigating the comparative roles of multi-source factors influencing urban residents' transportation greenhouse gas emissions," Science of the Total Environment, vol. 644, pp. 1336-1345, 2018.

[20] J. Yang, "The impact of environmental pollution on leisure sports activities of urban residents," Journal of Coastal Research, vol. 104, pp. 913-916, 2020.

[21] Z. Yang, Y. Lin, S. Wang et al., "Urinary amino-polycyclic aromatic hydrocarbons in urban residents: finding a biomarker for residential exposure to diesel traffic," Environmental Science and Technology, vol. 55, no. 15, pp. 10569-10577, 2021. 